\title{
Distributed PV Systems an Advantage
}

\author{
Vinita Mehto ${ }^{1}$, Prof. B.N. Phadke ${ }^{2}$ \\ ${ }^{I}$ Department of Electrical \& Electronics Engineering. \\ ${ }^{2}$ IPS Academy Institute of Engineering and Science Indore (M.P.)
}

\begin{abstract}
Distributed solar photovoltaic (PV) systems have the potential to supply electricity during grid outages resulting from extreme weather or other emergency situations. The PV input energy (Solar Irradiance) for electrical power generation is distributed everywhere, as such this distributed power generation will be boon for electrical energy source. As such, distributed PV can significantly increase the resiliency of the electricity system.

The ever increasing population leads to increase in energy demand. To meet this demand, distributed power generation systems are penetrated into the power system to form a new type of power system, the distributed power generation. It can be connected to the main power to different sub power generator models or can operate autonomously. Distributed power generation system has the advantage of reducing blackouts, which affects the power grids. It could also reduce the adverse effects of terrorism, if electric supply is attacked. The deregulated power market is also an important reason for developing the distributed power generation. (1)
\end{abstract}

Keywords: photovoltaic, solar module, tidal energy, etc.

\section{Introduction}

Interest in PV systems is increasing and the installation of large PV systems or large groups of PV systems that are interactive with the utility grid is accelerating, so the compatibility of higher levels of distributed generation needs to be ensured and the grid infrastructure needs to be protected. The variability and non dispatchability of today's PV systems generated power affect the stability of the utility grid and the economics of the PV and energy distribution systems. Integration issues need to be addressed from the distributed PV system side and from the utility side. Advanced inverter, controller, and interconnection technology development must produce hardware that allows PV to operate safely with the utility and act as a grid resource that provides benefits to both the grid and the owner.

Today, the world is in need of such distributed generation which is continuous and clean. Previously, combustion generators were used as distributed generation or distributed energy. In some cases such generators were reliable and affordable, yet not clean. While keeping other options for distributed generation, the local grid is somewhat reliable within the area of few kilometers, the estimated cost for grid extension and abiding yield of electricity differentiate it from other sources. Nowadays, solar power has emerged as a good choice for distributed generation. But this source may be proved as a broken piece as the energy distribution is required for all the time even when sun is not present. Along with solar energy, wind energy is also a renewable and an environmental friendly energy with low maintenance cost. Wind energy can be used in various works like electricity, grain mills and energy storage etc.

A simple solar electric system consists of five parts, as shown on figure below.The five parts are solar module, rechargeable batteries, control unit, distribution of electricity and electrical appliances.

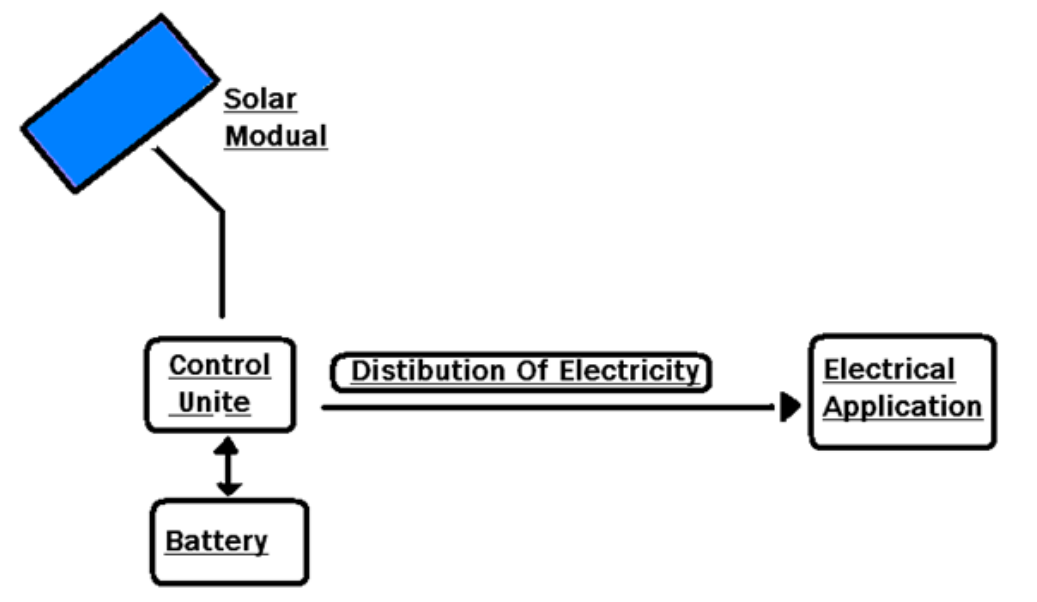

Fig: 1 Distributed Power PV System 
Solar module is used to generate electricity from sunlight. When electricity is generated, the control unit will take part, its function is to switch the loads manually or automatically, protect the batteries and wiring, monitor the performance of the system and to give warnings when faults happen in the system. Some simpler system may not have control unit. The rechargeable batteries are connected directly to the solar module.

\section{Solar Energy Conversion System}

The block diagram of solar energy conversion system is shown in figure 2.It includes a modeled PV array, boost converter controlled by incremental MPPT algorithm. Then it is connected to the Dc link. This DC link connected to the grid trough multilevel inverter.

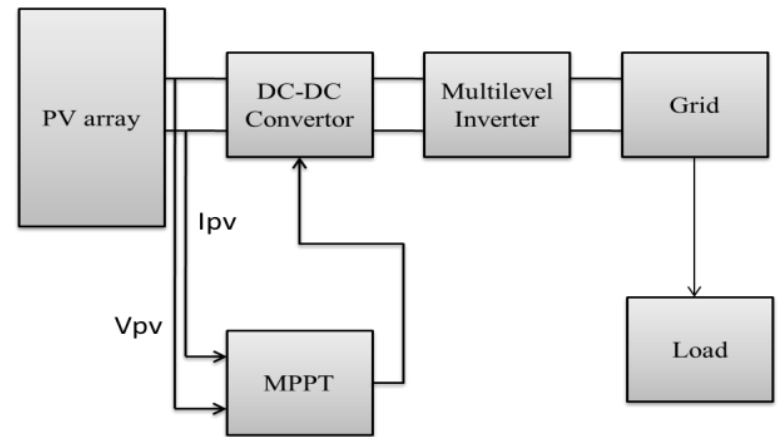

Fig: 2 Solar Energy Conversion System

\section{Distributed Pv Generation Is Categorized Into Following Two Categories}

\section{Mini Distributed Generation:}

$>1 \mathrm{KW}$ : It is easy to construct and installation is simple. It requires 10 square meter land so it can be mounted on the ground or roof top. Cost of land is negligible. Maintenances are low as there is no moving part, aesthetically pleasing.

$>10 \mathrm{KW}$ : Construction is simple; it is fully automatic no operator is required. It occupies 60 square meter area. It has 40 solar panel of 250 watt. It can be installed in one day only. Life of this plant is more than 20 years. Installation cost is about 5.5 lakes (US \$ 10,000). It produces power at least $18000 \mathrm{KWH}$ in a year.

> $1 \mathrm{MW}$ : The land required for $1 \mathrm{MW}$ solar power plant is around $4.5-7.5$ acres. This is only a rough benchmark and may vary based on technology and efficiency of panel. Life of this plant is more than 20 years. Energy generated is considered as 1.5 million units. It is only a rough benchmark it is not actual value. The actual energy generated is depends upon both internal and external factors.

\section{Applications of Mini Distributed Generation:}

1. ATM.

2. Call centre.

3. Form houses.

4. Fuel pumps station.

5. Guest houses.

6. Hospital.

7. Hotels.

8. Internet centers.

9. Laboratories.

10. NGOs.

11. Residential colonies.

12. Software development.

13. Transmission and communication towers.

14. Village electrification.

\section{Macro Distributed Generation:}

More than $100 \mathrm{MW}$ : The land needed for the implementation of $100 \mathrm{MW}$ power plants is about 8-10 acres. These power plants have large capacity to generate solar power among other available power plants. Multiple products which are energy intensive products can utilized this free energy for their production, like aluminum, glass \& all batch production material. Energy generated in excess of the current demand can be fed to grid without creating any serious issues with regards to load balancing and economic dispatches. The PV's and the loads being close the net results will be win-win situations for PV's and Grid balancing. 


\section{Solar Energy Distributed Plant In India}

In terms of power generation India holds the sixth position. In July 2009, under National Solar Mission, India has publically broadcasted plan to yield 20,000 MW of solar power by 2020 .

\section{1) Gujarat}

Gujarat was the first state in India to announce a dedicated rooftop policy. During the first phase, 5 MW was implemented in the city of Gandhi Nagar. The model is now being rolled out in five other cities of Gujarat, aimed at creating a total of $25 \mathrm{MW}$ of rooftop solar power. The Gujarat government announced that it plans to install a total of about $60 \mathrm{MW}$ by 2017 through rooftop units on residences. The current policy functions on a 'gross metering' model, where a fixed, preferential tariff is paid to the generators for each unit sold to the grid. However, it is likely that Gujarat will soon move to a net-metering route for promoting rooftop solar.

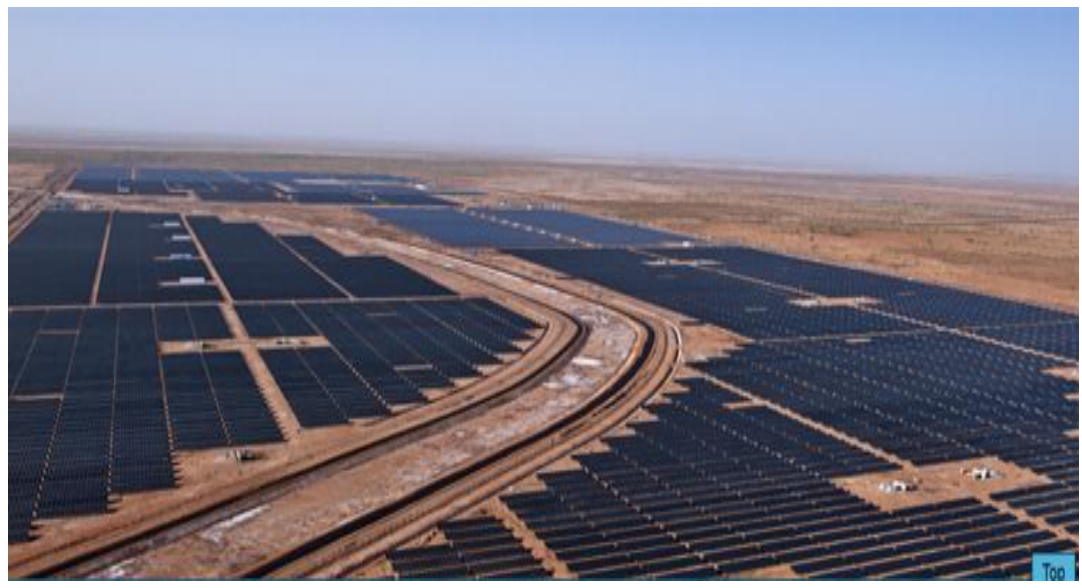

Fig: 3 Gujarat Solar Plant

\section{2) Uttarakhand}

The Uttarakhand Renewable Energy Development Agency (UREDA) has released its policy 19, aimed at promoting grid-connected rooftop and small-sized solar PV power plants in the state in August 2013. The scheme offers a net metering facility for grid connected rooftop solar plants. The solar system owner will be compensated for the excess power supplied to the grid at a tariff of INR 9.20/kWh. Eligible plant capacities under the scheme are $300 \mathrm{~W}$ to $100 \mathrm{~kW}$ (with battery) and up to $500 \mathrm{~kW}$ (without backup). The policy aims for $5 \mathrm{MW}$ by 2015 . Technical details have not been addressed so far.

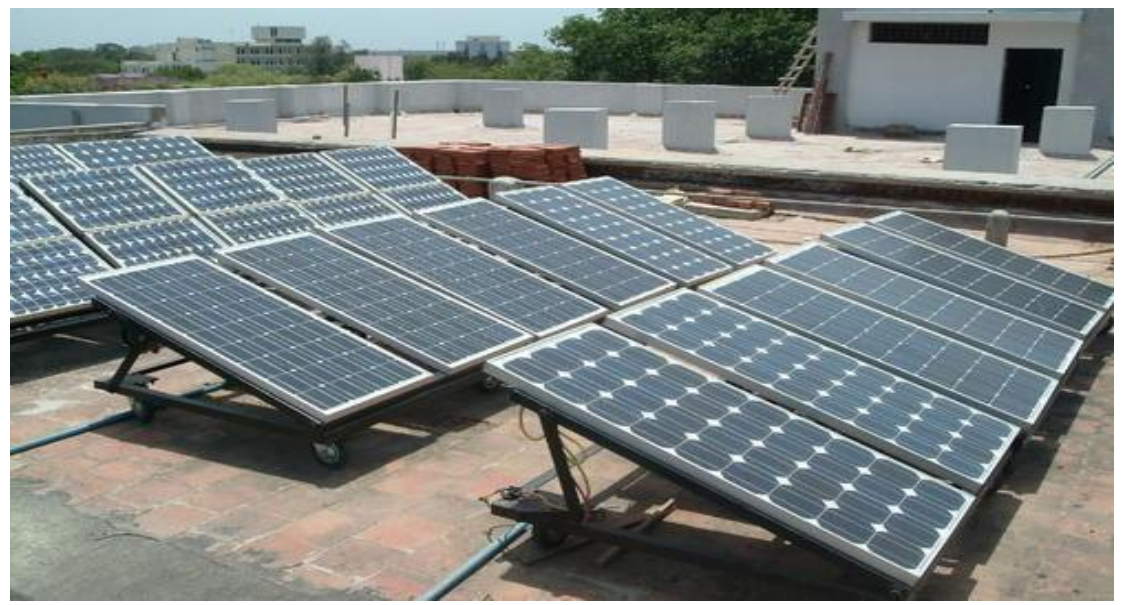

Fig: 4 Solar Plant in Uttarakhand

\section{3) Andhra Pradesh}

Andhra Pradesh announced its net metering policy 17 in March 2013. The policy is limited to consumers with three phase connections. This unfortunately does not include most residential consumers who might want to augment their current consumption with solar to hedge against a rise in the price of electricity. However, the government has decided to provide a $20 \%$ subsidy for rooftop solar systems up to $3 \mathrm{~kW}$ 
capacities, solely in the domestic consumer category, in its order 18 of June 2013. The surplus energy injected into the grid will be compensated by the APDISCOMs at the pooled cost decided by the Andhra Pradesh Electricity Regulatory Commission (APERC) for that year. The settlement of the surplus energy injected will be on a half yearly basis for seven years. Technical details of the net metering system have not been addressed so far.

\section{4) Tamil Nadu}

In Tamil Nadu, about $90 \mathrm{~km}$ from Madurai, there is solar photovoltaic power generating station named as Kamuthi Solar Power Project. Power has this project. Kamuthi Solar Power Project is the world's largest single location solar project having generating capacity of 648MW. The project was completed on 21 September 2016 with the cost of about 4,550 crore rupees. The setup has been installed with 2,500,000 solar modules and 27,000 metres of structures along with 576 inverters and 154 transformers with cables upto $7500 \mathrm{~km}$. The power plant yields $11 \mathrm{MW}$ of energy per day.

\section{5) Madhya Pradesh}

In central India, The Welspun Solar MP project is situated in very small village of Madhya Pradesh. The setup has been built in small village named Bhagwanpura, south of Diken, Jawad tehsil of district Neemuch in Madhya Pradesh. The power plant is capable of producing 151 MW of energy through its photovoltaic system. The $85 \%$ of the generated energy is assured to by local load balance is delivered to the grid. $25 \mathrm{MW}$ of energy supplied to the grid during the day time can be easily absorbed by grid without affecting its normal operation. The solar PV modules used in power plant depend on photovoltaic technology of polycrystalline silicon. The power plant has started its operation since February 2014. The Welspun project has been constructed over 305 hectares (750 acres) of with a cost of 1100 crore rupees. The project claims to supply power at 8.05 rupees per kWh. Welspun Solar Madhya Pradesh Private Limited (WSMPPL) is a subsidiary for Welspun Energy Ltd. (WEL) which has constructed the solar plant. This plant assures to mitigate carbon emission around 216,372 tons annually, with supplying power to 624,000 homes. The life time of the Solar PV power plant is estimated in 25 years. The plant would be responsible for exporting the electricity to the regional North-East-West-North East (NEWNE) electricity grid in India, after electricity being stepped up to $132 \mathrm{kV}$. Through the upcoming projects, this solar generating firm in Madhya Pradesh is on the mission to lower down the poisonous carbon dioxide.

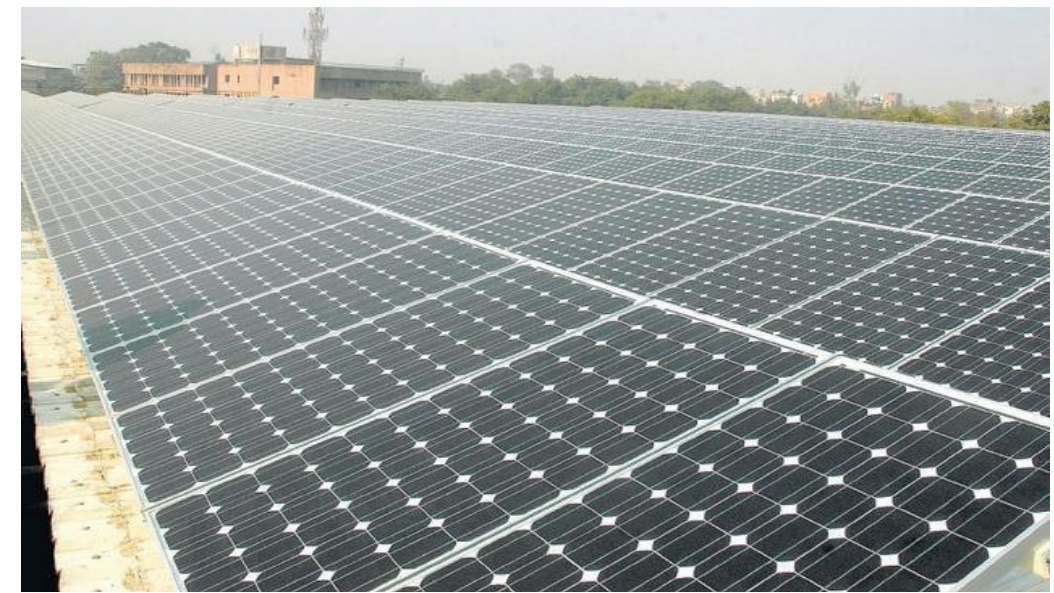

Fig: 7 Solar Plant of Neemuch, Madhya Pradesh

\section{6) IPS PV Power Plant, Indore}

IPS photo voltaic power plant is a rooftop plant installed in Indore. This rooftop has $28 \mathrm{~kW}$ of capacity to generate solar power. It has two units, each of $14 \mathrm{~kW}$. These units are established in the recent years and came into existence in the year of 2014 and 2016 respectively. One unit of $14 \mathrm{~kW}$ accesses battery for storage and another unit are connected with inverter directly. The power plant aims to generate $48 \mathrm{Vdc}$ power supply $(220 \mathrm{~V} \mathrm{ac})$. For the maintenance of the power plant, cleaning is done at the regular intervals to maintain its efficiency.

The working hour of college is in between $9 \mathrm{am}$ to $5 \mathrm{pm}$ and almost $100 \%$ energy needs can be tapped from the photovoltaic system.

Apart from the above Welspun and IPS PV solar plant, Madhya Pradesh has a wide list of solar power plant proponents. 


\section{7) Solar rooftop for Indian Railways}

The government has put a step forward in the area of distributed power plants. It has been decided to build a renewal setup for power plants which may serve as the rooftop for Indian railways. For this, a renewable energy development company, which is a power venture for renewal has won bids for solar power plant installations at various places in India for the railways. These setups have approximate 5 MW generating capacity. This company is expected to invest about Rs 35 crores to supply energy to Railways through these projects in 25years through power purchase agreements.

Table 2 This 5 MW production of solar energy has been divided into various zones of Indian railways.

\begin{tabular}{|l|l|l|l|}
\hline Sr. No. & Allocated Capacity & Railway Zone & Railway Division \\
\hline 1. & $1 \mathrm{MW}$ & North Central Railway & Allahabad, Kanpur \\
\hline 2. & $1 \mathrm{MW}$ & South Western Railway & Bengaluru, Hubli \\
\hline 3. & $1 \mathrm{MW}$ & East Coast Railway & Vishakhapatnam \\
\hline 4. & $2 \mathrm{MW}$ & South Eastern Railway & Kharagpur, Adra, Chakradharapur, Jamshedpur \\
\hline
\end{tabular}

These projects in combined manner can generate annual power more than 7 million units with an offset greater than 6000 tones of carbon emissions per annum. Renew Power setup has yield of about 3,000 MW through commissioned and clean energy capacity which are still in under construction all over India across Delhi, Gujarat, Haryana, Punjab, Madhya Pradesh, Rajasthan, Maharashtra, Karnataka, Telangana, Jharkhand, Uttar Pradesh, West Bengal, Tamil Nadu, Himachal Pradesh and Andhra Pradesh. These agreements will add significant results in saving cost of energy for Indian railways without any investment.

\section{South Eastern Central railway, Raipur:}

South Eastern Central Railway region has previously installed power plants having capacity of 218.18 KW in total. This project is set to enhance the utilization of solar energy further. Therefore, the South Eastern Central Railway is now set to install solar power plants on roofs of SECR buildings like Central hospital and multi department's training centers under Public Private Partnership (PPP) model. The rooftop power plant will be of four MW and grid connected. Uslapur electrical training centre would set to have a 100KW plant whereas Railway recruitment board and Bilaspur railway station will have plants of 50KW each. Furthermore, many solar panels will be installed at many places under the South Eastern Central railway solar project like training schools, railway hospital, running room, and level crossings. It is aimed to make Bhanwar Tonk railway station as a solar power dependent to run and work because the area doesn't have power supply.

\section{East Coast Railway, Bhubaneswar:}

To mitigate the effect of greenhouse and in order to conserve energy, the East Coast Railway (ECoR) commissioned two solar power systems of $50 \mathrm{~kW}$ power each mounted on the top of its headquarters at Chandrasekharpur. The solar power plant has been inaugurated by ECoR's general manager Rajiv Vishnoi. These solar power systems are aimed to save 450 units of electricity per day. Entirely, the structure is spread over a floor area of 1,200 square meters.

Table 2 Different Solar Plants Details

\begin{tabular}{|l|l|l|}
\hline State & Date of Launch & Capacity \\
\hline Gujarat & September 2011 & 5MW \\
\hline Andhra Pradesh & March 2013 & Not specified \\
\hline Uttrakhand & August 2013 & $5 \mathrm{MW}$ \\
\hline Tamil Nadu & September 2016 & $648 \mathrm{MW}$ \\
\hline Madhya Pradesh & February 2014 & $151 \mathrm{MW}$ \\
\hline
\end{tabular}

\section{Conclusion}

Distributed solar PV is expected to grow significantly in the coming years because of increased economic viability for certain consumer segments (commercial, industrial and high-use residential) in particular geographical areas in India. While many states have already put in place favorable net metering policies, some state ERC regulations support rooftop projects through the feed in tariff route. The key point is installations of PV's in the range of few kilowatts energy generation can be set in a short time which will immediately start reducing carbon foot prints and at the same time generate immense scopes for mass work distributed over a broad spectrum of skills. By some estimates, India could install 3 - $5 \mathrm{GW}$ of distributed solar in the next three five years. 


\section{References}

[1] H. Willis, ed., Distributed Power Generation: Planning and Evaluation, Boca Raton: CRC Press, 2000.

[2] Chalmers, S.; Hitt, M.; Underhill, J.; Anderson, P.; Vogt, P.; Ingersoll, R. "The Effect of Photovoltaic Power Generation on Utility Operation." IEEE Transactions on Power Apparatus and Systems; PAS-104, 1985, pp. 524-530.

[3] Patapoff, N.; Mattijetz, D. "Utility Interconnection Experience with an Operating Central Station MW-Sized Photovoltaic Plant." IEEE Transactions on Power Systems and Apparatus; PAS-104, 1985, pp. 2020-2024.

[4] Proposed Gujarat Solar Policy Tariffs for period 29 Jan 2012 to 31 March 2015

[5] Welspun Energy Ltd. 151 (DC) MW Solar Plant, Madhya Pradesh, http://www.welspunenergy.com

[6] "India's largest solar plant in MP, Modi calls it saffron revolution". www.thehindu.com. The Hindu. 26 February 2014. Retrieved 24 August 2014.

[7] Solar Projects, Welspun Renewables. Wels 